\title{
Completes the Course but Fails the Degree from Regular Schools
}

\author{
Yujia Feng
}

\section{Interview with Mr. C's Father}

C, male, born in 1986. Only child. Grade IV intellectual disability. Completed courses in regular primary school, middle school, and technical school. He entered the Sunshine Home in Hongkou District, Shanghai, in 2007.

Interviewee: C's father

Interviewer and writer: Yujia Feng

Interview dates: October 28, 2016 and May 9, 2017

Interview place: Star Sky Cafe

\section{He Wasn't Clever Enough to Study}

Q: May I ask how you and C's mother first met?

C's father: My wife and I met each other through a mutual friend in 1984; both of us worked on the Qianwei Farm on Changxing Island. ${ }^{1}$ Our jobs were pretty good, she was an accountant, I was chief of the sales section. We got married in 1985, a year after we met. We had a permanent contract with the Qianwei Farm, which meant that we'd promised to settle down on the farm for life. It was a popular way to settle down for the future for youth workers at that time.

\footnotetext{
${ }^{1}$ The Qianwei Farm is a state-owned farm on Changxing Island, Chongming County in Shanghai. The farm was established in 1958 and had been combined with several other farms or companies. Now it has over 30 farms, orchards, and companies.
}

Y. Feng (更)

Fudan University, 220 Handan Road, Shanghai 200433, China 
Q: When was the child born?

C's father: We got married in 1985 and had our son the following year. My wife had health problems during the pregnancy, high blood pressure, so she went to the hospital quite often, she even spent 2 or 3 months in hospital.

The doctor told us she had high blood pressure and the fetus was under average size. Because of these problems, she was kept in the hospital for a month before the due date. The doctor said she needed to eat more, but she didn't have any appetite at all; she ate pigeon soup for three or four meals over 2 days. In August, the baby became overdue and the doctor suggested having a caesarean. My son was only a little more than $4 \mathrm{lb}$ when he was born, a full-term baby with a premature baby's problem, birth defects. According to the medical knowledge about his situation, he would be more difficult to bring up than other premature babies. Later, while he was in an incubator, he caught a cold, the doctor found out he had congenital heart disease and pulmonary insufficiency. We had to keep one eye on his condition.

When he was a month old he got pneumonia, so I took him to the People's Hospital. The doctor told me he had to be hospitalized, but I just thought at his age, he shouldn't be kept in hospital and the doctor let me decide what to do. It was just the beginning of pneumonia, he didn't even need an injection, so we fed him some Jiemycin pills. The pills cured him, his cough stopped, and his fever went away.

After that, I went back to Changxing Island to work, my wife was still on maternity leave, but they came with me. From that time, my son went to hospital every few days. I remember one evening when I came back home from work, it was almost 8 o'clock, he was crying badly, my hugs wouldn't stop him either, so my mother-in-law and I took him to see the doctor again. The doctor told us he had a hernia; at such a young age, an infant can have a hernia. So the doctor gave him a slow massage and he was healed.

From 1973, I worked on the farm for over 10 years, so I knew the farm's doctor very well. The doctor suggested that we have another child, but I didn't want to do that because bringing up one child was difficult enough. At that time, we didn't realize he would have learning difficulties. The doctors were only concerned about his physical condition, but they didn't mention any possible mental problems. When he was 2 or 3 years old, he was a very active child, friendly with everybody. One time our department organized a tour to Huangshan, and I took him with us. He walked down the mountain on his own, saying hello to everyone all the time, he was a such a bouncy and active boy.

Q: Who looked after him between the age of two and three until nursery age?

C's father: My mother-in-law, his maternal grandma, brought him up when he was little. Nobody could tell that he was intellectually disabled from his childhood pictures.

Q: Did he stay at the nursery?

C's father: He attended nursery, a good nursery in Qianwei New Village. He started there at the right age, but my son didn't get on with the other children. He always focused on his own things, never took a noon nap like the other children, he was very naughty. Basically, he could do some things very quickly, but wasn't good 
at other things. For example, the nursery served a light meal every day, and he used to be the first one to finish the snacks.

He was very funny when he was a little boy. We were new parents, very keen about the way he was dressed, we tried to make him look adorable. He was also a very active child and his teachers liked him very much, too.

Q: When did you find out he had a learning difficulty?

C's father: Only when he went to school, we just realized there was something wrong. He spent 1 year in a school on Changxing Island, but didn't do very well. The teacher said he always thought that there was something not quite right about my son. Then, I took my son for an intelligence test at the Women and Children's Hospital in Hongkou District and the result wasn't too bad, so I decided to let him stay at school. But there were more problems with his behavior and we found out he was hyperactive. A prescription from the doctor improved his condition and the teacher later remarked on this improvement.

Actually, he passed the school entrance test; the teacher asked him some questions about his everyday behavior and some math questions as well, but he couldn't keep up with the pace at school.

Q: Did he have other problems except for hyperactivity?

C's father: Nothing typically, just hyperactivity, some people said his problem might come from a birth defect. We never believed that he could be intellectually disabled.

Q: Do you remember how you felt when you had to take your son to see the doctor because of his learning difficulties?

C's father: It was a very bad time. He was our only child and we always wanted him to be a healthy boy, but... We found out that he had learning difficulties in his first year at school. There wasn't a hint of a problem before that moment; he was an ordinary child until he was 4 or 5 years old. My bosses liked him very much, he was small and cute, very funny, a sweet talker, but he was a slow learner.

Our farm had flexible working hours, so I could take and bring him back to school every day and I even made lunch for him. My office was near his school and I spent quite a lot time looking after him. Later, I moved to Shanghai for some new business for the farm, also, as an accountant, my wife had to travel to Shanghai quite often. When we were away, my wife's apprentice, a colleague, or his maternal grandma would look after the boy together. The apprentice was very strict with his homework, he seemed well behaved when he was with her, but his class performance was bad. He couldn't engage with the class at all, but there was nothing we could do about that.

Q: When did you find out that he couldn't keep up with the pace at school?

C's father: That was later. I moved to Shanghai for work, so I also moved my son's Hukou around 1992 when he was 6 years old and sent him to a new school where he started the first year again. On school days, I used to drive him to school on my electric scooter and later my sister would take him back to her place and make dinner for him. I would drive him back home afterwards. Sometimes, my wife helped me if I didn't have the time. Both us were very busy, we worked all the time, especially me. 
After he'd been in school for a year, the teacher asked: "Why did he leave the farm school?" I told him because I'd changed job and moved our Hukou, the household registration address. Then, the teacher asked me to get an intelligence test for my son, but the result from the Shanghai General Hospital revealed he wasn't too bad, and he was able to stay at the normal school. So we let him to carry on there. In the first year, his grades were not so good, usually around $70 \%$, but they dropped in the second year. He just about passed the exams at $60 \%$. In the third year, he failed completely. This time I took him to the Longhua Hospital for another test. The doctor said his IQ was below average, but not too bad. The teacher would only allow him to stay if his exam score didn't affect the class average score for the school.

Q: Did the doctor tell you why he had this intellectual problem?

C's father: The doctor said an inherited defect was the only reason that could cause his problem.

Q: Did you try to help him catch up with his studies after you found out about his learning difficulties?

C's father: At that time, my wife and I were very busy with our work and at the same time, because of his condition, private tutorials didn't work well for him. As parents, we could only teach him some simple things.

Another thing that concerned us was he was getting bullied at school. His class mentor was a very nice person and contacted us from time to time. She said she could only keep an eye on him during class time, but there wasn't very much she could do if he was bullied by somebody outside the classroom. So she kept asking us to tell my son not to stay out for too long.

\section{He Has Three Pass Certificates but Never Finished His Education}

\section{Q: Did your son study in a special school?}

C's father: No, he didn't. He studied in the Hailun Road School from his first to fifth year. Once his mom and I visited the Special School at Miyun Road; we saw some of the students were sleeping outside during class time, but the teachers didn't stop them.

I thought my son isn't a very smart student and he's just going to get worse if we send him to that school. Even though there were some students with a better mental condition than my son, the campus was quite messy and busy. So, I thought, our son isn't too bad, it would be better to send him to an ordinary school and at least give him a chance. Otherwise, he'll waste his time at the special school.

At the end of primary school, he only got a pass certificate. Then he studied at the Jian'an Middle School, and, to be honest, he was just mudding along there and we knew he couldn't make it.

The middle school teachers looked down on our son as well, they thought he brought down the average scores for the class. They told us: "Your son has affected the quality of our class." We had to ask the schoolmaster: "Would you let our son stay if he doesn't bring down the GPA for the class?" With his permission, the boy 
got a chance to study there. He spent 3 years there until he finished with another pass certificate.

The school is the same as everywhere else, it has its bullies as well. He's been bullied since he went to primary school. I went to his school many times to ask the teachers to protect him, at least give him a little bit more attention on campus. For example, I asked them to stop my son going outside during the break and to go back home directly after he finished.

The years he spent in middle school were very tough, even worse than when he was at the Vocational School; the discrimination got worse as he grew up. People can be aggressive, like racism, it's the same kind of discrimination between non-disabled and disabled people. There's nothing we can do about it.

Q: Did he have some close friends at school age? Did he meet some good teachers who cared about him?

C's father: None. Even though the Jian' an Middle School was the lowest ranking school in Hongkou District, they still had their own teaching quality targets to meet. It was for this reason that he was told to leave by the teachers.

Q: How about other people's attitude towards the child, other than the teachers and the classmates?

C's father: Discrimination is common in our society. Nobody insults our son to our face, but sometimes some neighbors who are close to us told us: "Somebody talked about your son behind his back." Anyway, it's not a surprise to us, we have a special child, people won't accept that easily.

Q: Did you help with his homework when he studied at school?

C's father: We helped him with his studies when he was in primary school. When he studied at middle school, it was beyond my ability, because I'm only a middle school graduate.

Q: Did he get annoyed with your preaching and teaching?

C's father: Sometimes he said it was terribly annoying. It's a very difficult situation. He can be frightened by strangers, but then he won't take someone who he knows seriously.

Q: What did he study at the Primary Vocational School after he graduated from the middle school?

C's father: Later, when he went to the Shanghai Qiuzhi Vocational and Technical School on Quyang Road in Hongkou District where he majored in Electrical Engineering. He couldn't engage with his studies, he was there to make up numbers. The grade was the last thing we needed to worry about. My son's weakness is that he has no desire to succeed and has very poor practical abilities. He's very fast and good at the things he wants to do, but he won't make any effort with anything he doesn't like. For example, he likes watching TV and football, and he knows all the singers of popular songs, but he has terribly poor practical ability. His middle school teachers told me the same thing.

He started vocational school in 2004. The teacher was very nice, he kept in touch with us frequently. One time he suggested that we do another intelligence test and apply for an intellectual disability allowance; I guess because at that time the school had a special policy for disabled students. So, this time, we went to the Mental Health 
Prevention Center at Longhua Hospital and the test result revealed that the degree of his disability was not considered to be serious.

In the meantime, I was working in Shanghai, so my wife spent more time on our son's case. She consulted with the Shanghai and district Disabled Persons' Federation (DPF). She was told she had to get a document and medical certificate from Longhua Hospital first and then take them to the subdistrict office for a certificate of disability.

Finally, my son got the third pass certificate from the Primary Vocational School. He never spent any time doing his electrical engineering course homework, I was always the person to finish his homework for him. He completely failed in his studies, he never engaged with the class, and he even damaged some equipment. But what could we do? The school was close to our home, so we just let him spend his time there. He walked between home and school by himself.

$\mathrm{Q}$ : What did he do after he graduated?

C's father: His paternal auntie retired in 2001, so after he graduated from school, his auntie looked after him until he joined the Sunshine Home in 2004. People like us are really proud, we hardly socialize with the outside world; my wife is very introverted, a very private person, she doesn't like to take our son out or let him go out on his own.

I remember once, it was a very hot summer day, I hadn't been home for a whole day. I found out that my son, stuck at home with my wife, got angry and vented his anger by poking an electric fan with a ball-point pen; the fan was a mess. He thought we'd locked him up at home even though he begged us to go out, but we were worried he might get bullied by somebody if he went out alone. I don't mean we look down on ourselves, but his condition is bad enough, if he's being talked about or bullied... We can't explain ourselves to other people, it's not worth trying to discuss it, anyway, he's just not a clever boy. In our society, discrimination against a child like him is common.

When he was born, our careers were going through an unsettled period. We had lots of unusual experiences and didn't look after him properly. A child like him might get bullied by some people if he doesn't get plenty of love and attention from his parents.

Q: What's do you mean by unusual experiences?

C's father: Back then, as new workers on the farm, we were disliked by some people. The only way to overcome this situation was to work harder, to volunteer for heavy work. The only way to learn new skills was by watching experienced workers all the time, like a thief. People might talk about you if you were a slow learner. I tried all kinds of jobs before I joined the supply and marketing section, plasterer, tiler, painter, carpenter, and the dean of the carpentry shop. I came to Shanghai to start a new career and tasted the thrills and spills of life. Once I didn't rest for over 2 days and a night.

Q: What do you mean when you say you didn't look after the child properly?

C's father: These days, children with at least one parent spend all their time raising them, but in our family, both of us focused on building a new business and we didn't give the child enough attention. 


\section{The Sunshine Home Is Great}

Q: When did he go to the Sunshine Home?

C's father: We didn't want to keep the child at home all the time, so again my wife went to the subdistrict office for advice. The office suggested that we send our son to the Sunshine Home, so he started there in 2007. He joined in some sports and activities there; he also joined the district DPF center's drum team. Later, he participated in the district DPF Sports Meeting, which took place on the Fuxing Middle School's campus. He played badminton, sprinting, and sit-up games and he wasn't bad.

Q: Why did he enter the competition, because he likes sports or you wanted him to develop special skills in the field?

C's father: Neither, just because the teachers of the Sunshine Home asked him to, then he joined in some games. I remember years ago, around 2007 or 2008, he went to the Intellectually Disabled Persons' Talent Show in the area a couple times. Another show he has involved with was a performance of A Grateful Heart, a singing show with sign language. The teacher invited my son to do that performance as well. He worked very hard and practiced at the Sunshine Home every day, and I helped with his practice at home too. I found online sign language videos and kept him company while he studied them. Their performance nearly won the Shanghai competition prize.

I usually say my son is a total "dud." If you let him do something, he'll have a go, but he won't spend much effort on it. I think boys don't have the same self-motivation as girls. For the first few years at the Sunshine Home, he was a pretty good student. He was the class monitor for a half year, but after that, he just let himself go, he lost his appetite for hard work. However, some of his classmates' parents said he was a kind person.

These days at the Sunshine Home, he isn't very practical; for example, he can't bake cakes or do this kind of job. Several times, the teacher told me to let him practice eat home, but he just doesn't want to do that. Sometimes, we make wonton together, but he just messes around, it takes me much longer to clean up. The only thing we can let him do is wash up after dinner.

Q: What does he usually do at the Sunshine Home?

C's father: They do all kinds of things there, they have singing classes, the teacher is a special-grade teacher, sometimes he would talk about it and sing to me after they learned new songs. Recently, they learned the Spanish song, Carmen March, he likes to listen to it online and enjoys it very much. Actually, he likes music, but he can't sing. They have a drawing class every Wednesday and some other classes like reading and calligraphy, but now the calligraphy class has been replaced by a drawing class. He's pretty good at drawing, he likes water color painting very much.

Sometimes parents talk about the Sunshine Home, and compare them with other homes in Hongkou District. We feel that our Jiaxing Subdistrict Sunshine Home is the best of them. The teachers are very nice too. 
Q: What was C's favorite course from primary school to vocational school?

C's father: He liked to watch TV and play with the computer. Children's programs are his favorite, for example he likes Hade Strong, ${ }^{2}$ Ultraman. ${ }^{3}$ He also likes to watch Amazing Detective Di Renjie 4 and some foreign war programs.

$\mathrm{Q}$ : What was his favorite course?

C's father: He doesn't like studying or learning any kind of skills, but he'll be very happy if you allow him to listen to music, watch TV, or play on the computer. He isn't interested in other things, he can't even sew the holes in his socks or put a button on his clothes.

Q: Does he like to go out with his classmates?

C's father: My son has to travel from the Baoshang District to the Jiaxing Subdistrict Sunshine Home by bus, because we don't live in the place of our Hukou registered address. So we're a long way from his classmates who live around the Sunshine Home, but they play together at the home. These children are very naïve, more like 7- or 8-year-olds, they like singing, playing, and bouncing around together.

Q: Did he make some close friends after he joined the home? Did he mention them when you were together?

C's father: Yes, of course. He likes to talk to me about his classmates and teachers. He likes to tell me the result of their Thursday badminton game and he says if the class monitor is his partner they always win. Actually, he always enjoys the game, it doesn't matter if he wins or loses.

Q: Does he like to chat with his teachers?

C's father: The teacher said my son talks too much. Sometimes he likes to interrupt the teacher when the teacher is speaking, and he likes meaningless chatter. My son used to take part in almost all of the activities, but he stopped a couple years ago.

Q: Why did he stop recently, did he want to?

C's father: Not really. Anyway, he isn't a practical kind of child; he joins in games if the teacher needs to make up numbers. The teachers always like the active ones who have the potential to win.

Q: How does he usually get to the home?

C's father: He goes to the home by himself. I probably went there with him once or twice after we moved; he always travels between home and school by himself. If he wants to visit my sister, I only need to take him to the bus stop, and then he can change bus himself to get her place.

Q: How long has he been going to the Sunshine Home?

C's father: Since 2007.

Q: Do you think the Sunshine Home could be improved in some ways?

C's father: I'm quite satisfied with the home, because it's the best in the area. I've visited some other homes and the Jiaxing Subdistrict Sunshine Home is the

\footnotetext{
${ }^{2}$ Translator's note: Hade Strong is a character from the popular children's animation Boonie Bears.

${ }^{3}$ Translator's note: Ultraman is a famous and classic Japanese animation.

${ }^{4}$ Translator's note: Amazing Detective Di Renjie is a very popular historical detective program based on the story of the famous detective Di Renjie, who lived in the Tang Dynasty and served Queen Wu Zetian. The program is in its fifth season with over 200 episodes from 2004 until now.
} 
best. They run so many different classes for the students every week, like math, singing, drawing, and all sorts of things. The Leshanhui Foundation and other NGO groups visit to organize parties with the students. The chairman and vice-chairman of the Association of Persons with Intellectual Disability and their Relatives come on Thursday afternoons for a lecture on national and international politics.

Q: What does your son think about politics and math?

C's father: He's good at math, he has a very good memory and his mental arithmetic is pretty good. He listens to the international news, the Shanghai news, and he listens to the morning news at 6 a.m. every morning. If the teacher asks about the news of the day, he would be the first person to raise his hand in the classroom and he always puts his hand up in the chairman's international politics lectures.

\section{Sport Helps a Child Become More Sociable}

Q: When did he participate in Special Olympics and related events?

C's father: Two years ago. The teacher recommended him for a subdistrict sports event and he was chosen for the district competition on behalf of the subdistrict office, but he lost the game. In 2007 and 2008, he won a second and third place medal for the sprint events in the District Disabled Persons' Sports Meeting, which took place at Fuxing Middle School. He has so many certificates of merit we ran out of places to put them at home. Some of them came from the district or subdistrict events, but most of them are subdistrict event awards.

Q: What's his favorite sport?

C's father: He likes badminton and plays with me sometimes and he plays table tennis sometimes. He likes the games in the beginning but soon loses interest in them. He always plays a part in the subdistrict annual sports games and won several second and third place medals, but he never became a champion.

$\mathrm{Q}$ : Does he practice often?

C's father: I practiced badminton with him once, but it didn't go well because I was a member of the farm badminton team and he gave up soon. We're not a good match. And there were two teachers at the home who taught him table tennis.

Q: Did he practice with the teachers before the competition?

C's father: No, they don't practice together, they prepare on their own. He won a third-place medal in the darts competition; he did the all exercises by himself because the teachers didn't know how to coach him. It's the same thing for the sit-up game, he prepared by himself with a bar, that's all. Anyway, they're not athletes; improving their coordination is the main benefit.

Q: How did he become involved with sports?

C's father: I suggested that he try speed walking every day, because when we went out together, I realised he got exhausted quite easily. So he did speed walking every evening until recently and then he lost the appetite for it. I scared him by saying if he stopped exercising he might have a blood sugar problem when he had his health 
check in June. Actually, his blood sugar was normal, but he was really scared by what I said and took it seriously.

Q: How long has he practiced the side drum t the district DPF center?

C's father: Since 2008, and he enjoys it very much, because he can be creative. He was very good for the first few years and took part in all kinds of performances. For example, the band has a traditional comedy show called Three and a Half Sentences; he's the "half sentence" singer who makes jokes.

When my wife got cirrhosis in 2009, he stopped practicing for a while. She was frightened by this disease and stopped going to the side drum practice with him. Also, he used to get sweaty after exercise and all his clothes had to be washed afterwards. It was a lot of fuss, so we told him not to go there anymore.

My son's weakness is he won't focus on anything once he thinks he's learned it. I told him to rejoin the band in 2015, I took him there for the first 2 months, then after that he went by himself. Since then, he goes to practice every weekend except for the very hot summer holidays. I think going outside and doing some exercise, singing or studying English, is better than sitting at home and playing with the computer or watching TV. Recently, the district DPF center started baking classes, but my son isn't a big fan of this. For those students who like baking it's a very interesting and enjoyable thing to do.

He goes to the Sunshine Home by himself every morning, and if we ask him to buy some stuff for us, he can take the bus by himself to go shopping.

Q: Do you like to coach him when he plays the side drum? What do you think about his skill?

C's father: No, I don't do that. And his skill is average.

Q: Did he change in any way after he became involved in these activities and competitions?

C's father: He became more sociable and happier. He always tells me how wonderful his team is, how proud he is and that they're better than the others. He's such a proud person.

And his abilities have also improved; at least he's better skilled at communicating with other people. As a parent, I'm so pleased by his improvements, anyway it's a great thing to let him get involved in activities and win some awards. Children like him need to be praised, it's impossible for them to take criticism in the same way as children without disability. They're happy when they feel they can do something well and their hard work has been recognized (see Fig. 1).

Q: As a parent, you like him to take part in these activities?

C's father: Absolutely, I'm completely positive; because I really don't like him staying at home and watching TV or playing with the computer, I worry about his eyesight. The district DPF is so friendly with these intellectually disabled children. They arrange afternoon classes including drum practice, English, and dance every weekend. Some of the teachers and volunteers are also parents of disabled students in the group; I feel we're so close to each other, like a big family. We often chat with the teachers and others, now we're good friends.

Last Saturday, the district DPF office arranged a family trip to Disney Town. My son and another four or five children and two parents from the Jiaxing Subdistrict 


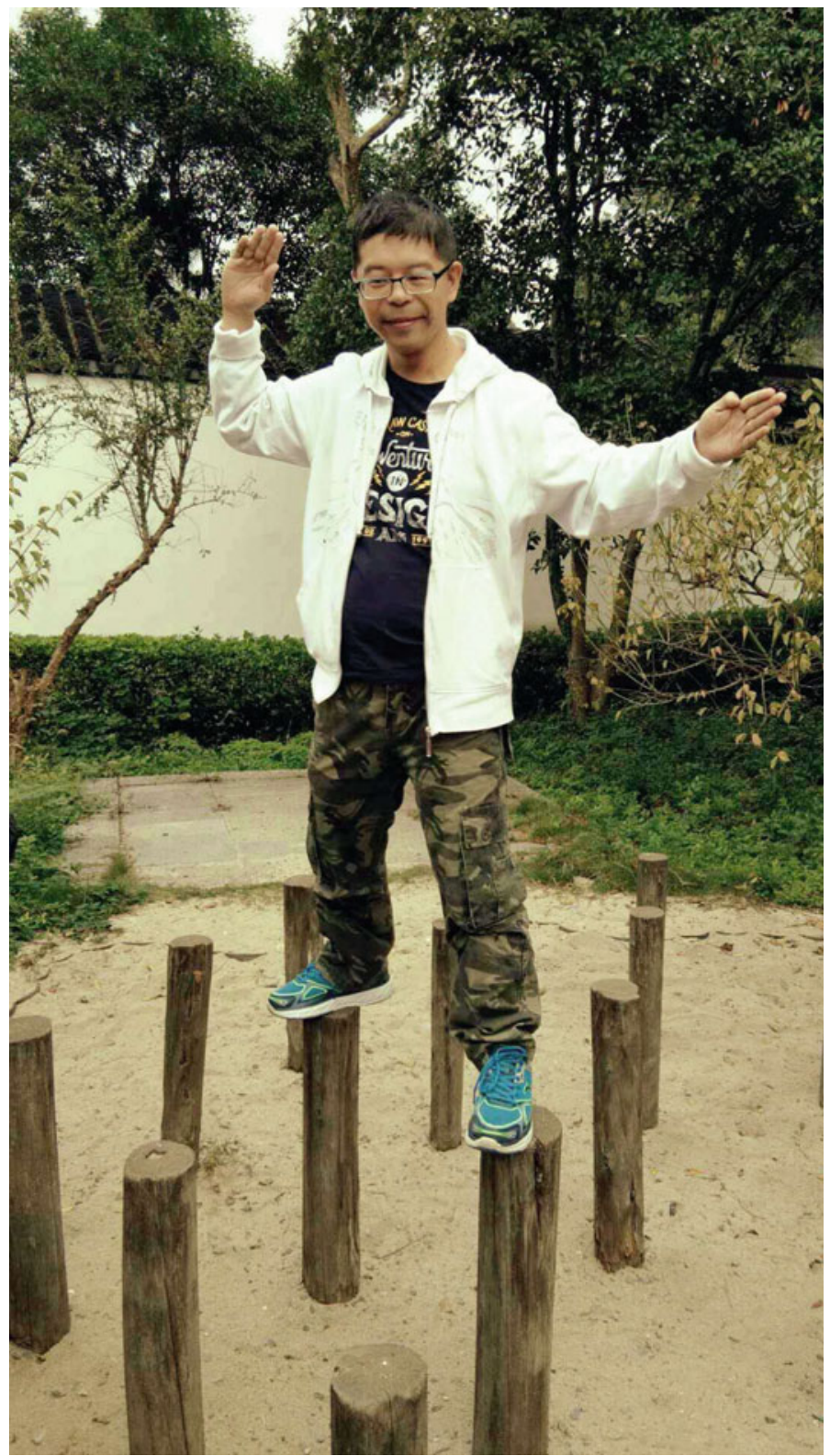

Fig. 1 Mr. C exercising on stakes 
Sunshine Home went together. This group life at the home encourages the children to be more sociable and friendly.

Q: Do you think it's useful to let him meet different people?

C's father: It's a good thing to let them keep in touch with society and also being close to other disabled children is good for him, but I don't like him getting involved with bad people. It's nice to talk with good people when you meet them. With my son's condition, we usually tell him: "Don't get involved in other people's business." One time, he told me he met a man who asked him: "Do you want a mobile phone?" So, I told him: "Don't talk to a person like this man again." But the good thing is he's aware.

\section{A Loving Family}

Q: Do your ideas about the child's education differ from your wife?

C's father: We don't disagree with each other most of the time, especially about the child. We've got on very well since we were married; we don't argue with each other at all, we don't mind losing as long as it's good for our son. We don't care what other people think about my son; we won't argue back if somebody says bad things about him to our face and we're always calm with our son and explain any situation to him carefully.

Q: What does your son do in his spare time at the weekend if he doesn't need to go to the Sunshine Home?

C's father: He likes to watch TV at the weekend. Sometimes I like to tell him to practice calligraphy to improve his handwriting. I always tell him: "You might not be able to change yourself, but you can have beautiful handwriting." But he doesn't like this idea because he isn't a patient person, and he gets frustrated when he can't do things right.

Q: Do you take him out at the weekend?

C's father: Of course, we started taking him out when he was very young, and he's visited a lot of places, such as Hainan Island, Huang Mountain, Zhangjiajie, Suzhou, Hangzhou, and many other places. We went to Huang Mountain when he was five, before he was school age, he was really an ordinary child, sociable and cheerful.

$\mathrm{Q}$ : What do you usually do when the family are together?

C's father: After dinner we like to talk about his day, about the Sunshine Home, the classes, some news - somebody went somewhere or somebody's family bought a new apartment... These students talk about quite lot things together.

Q: How about his life skills and independence?

C's father: He can look after himself; at the subdistrict office's summer campus, he could wash himself and his clothes, but cleanliness is not guaranteed. He washes his underwear occasionally by hand if you tell him to do so.

Q: Does he do the housework often?

C's father: If you say to him: "Pick some vegetables or peel some beans for your dad," he'll come and help. Sometimes, he washes rice and cooks it in the rice maker. 
The teacher always tells them: "You're not smart people, but at least make sure you can use a rice cooker and a washing machine. Then, you'll be fine when your parents get old." At the parent's meeting, the teacher also emphasizes the same things to make sure we're as keen as he is to help our children develop these skills.

But I haven't taught my son to use the washing machine yet, so he has to hand wash his underwear and socks.

Q: Do your colleagues and relatives know about your child's condition?

C's father: Most relatives and some very close friends know about him; I won't tell my acquaintances. I don't think his condition is a thing worth talking about with other people. Some people pity us, because a normal couple have a sick child. Some people say we should let him start his own family, but I don't think so, he isn't a healthy person and couldn't look after a family.

Q: Do you talk with the neighbors or your relatives very often?

C's father: My big sister cares for him a lot. She looked after him for a while when we moved to Shanghai; my wife and I were very busy with our work and hardly spent any time at home. My sister would take him to her place after school, my wife was only able to drop him off in the morning.

Q: Could you tell me more about how he gets on with his auntie?

C's father: His auntie doesn't have her own children and has lots of love for her nephew. She usually says: "I don't care what people think about him, nothing can stop me loving my own nephew." Actually, my son is very close to her and they like to play and joke together. During festivals and holidays, he usually asks us: "When will auntie come around? We should have a nice meal in a restaurant when she comes."

Q: When do you think your son began to change from when he was little?

C's father: In my eyes, he never grew up, but when my wife went for surgery in October, my son was there comforting her and giving her a massage; this made my wife so happy. She said to me: "Our son has changed and become a sensible boy now." Actually, we can see that he's growing up little by little and we think he's an understanding person now.

\section{What Will Happen to Him After We Pass Away?}

Q: Did you ever think about him getting married?

C's father: For sure, my son wants to get married, because he's 30 already. You can't say he doesn't want a family; of course, he has the desire. I told him that he can't start a family even though some of his classmates are married and have children. As the only child in the family, if he wants to get married, he has to find a person with the same condition. If by any chance they have a child like them, the whole family will suffer with the same problem.

Anyway, for the child's health, intellectually disabled people aren't encouraged to start their own family. Some good friends told me, if you want you could find him an ordinary wife outside of Shanghai, but I don't agree with this idea, looking after our family is enough for me. My wife and I are looking for social care for him. 
Q: What did he say when you told him your ideas of him getting married?

C's father: He just said, I see. I have to explain things very carefully: "What can we do for you if you find an intellectually disabled wife? What will happen to the whole family if you have a child who has a 70-80\% chance of having the same problem? We trust the science, it's a consequence of medical science that tells us this, so what can we do?"

Q: Did he have a job before?

C's father: Never. He wasn't a successful student, if he went for a job, what should I say...My niece, who works at a juice bar in Longhua area, was bullied in the workplace even though she's a normal person. My son might be treated even worse if he isn't good at the work. Besides, he isn't a practical person.

Q: Has he thought about finding a job?

C's father: Not really, and I don't want him to work either. My wife and I both have pensions that will be enough to support him. Our worry is what will happen to him when we pass away? What will he be able to do as an unemployable person when we are very old? Does society have any good policy and rules to support intellectually disabled people and their families?

Q: So you want better social care policy?

C's father: For sure, we do want more social care. My son is a small person, only slightly over 5 feet 2 in. tall, he isn't able to do a lot of things. For example, the district DPF office arranged around 20 lessons in a baking class for children like my son in the hot summer this year, but he couldn't do this work properly even if he tried, so I had to help him. In the end, it became my job. The class was from May to August, twice a month.

Q: Do you talk about your worries with your wife?

C's father: Yes, we do. Now we live on our pensions, but one day we'll get old, what can the government do for a family like us? We have to try our best to save some money for the future, to prepare for the day we get weak and old, but if we can't save any money, there's nothing we can do.

Anyway, "parasite singles," the ones who live off their parents, is a common social problem; children without disability are doing the same thing as my son. To be honest, at least my son is better than those troublemakers, he doesn't throw money away or upset us in that way. Compared to those young gamblers who come back home only for more money, my son is quite easy to look after.

Q: What kind of welfare does your son have at the moment?

C's father: His salary consists of two parts, the first part is $40 \%$ of the minimum wage in Shanghai, 2300 yuan-he gets 920 yuan for this; the second part includes three main subsidies: medical, unemployment insurance, and a pension. It's too low.

Q: What do you think about his welfare?

C's father: It's lower than those foreign countries. Compared to disabled people in foreign countries, especially intellectually disabled people, the social benefit gap is from the sky to the earth. My son only receives 920 yuan every month. Can you tell me that this is enough for his living expenses? No way. 
We have to say, in China, their benefits are getting better every year, even though they are still much lower than some foreign countries. For example, this year they started to receive a new subsidy of 45 yuan as a transportation allowance.

My son isn't considered to be moderately disabled, but you could say that his problem is more serious than mildly disabled. Years ago, I tried to get him to do another IQ test to find out the grade of his disability, because for different grades of disability you receive different benefits. But eventually I just let it go. Anyway, his salary is less than those severely disabled people, but at least he'll have a pension when he retires. The more serious people are severely disabled and unemployed, they have a higher salary but without those three additional benefits.

Q: What do you want for him for his future?

C's father: We only wish he has a good life in his old age and gets more disability benefit. Right now, we don't think about ourselves, but only our son. His salary is only $40 \%$ of the minimum wage, so it's not very much. And recently they have to pay 80 yuan a month for lunch at the Sunshine Home; they didn't have to do that before.

Q: What's your son's plan for the future?

C's father: He hasn't talked about a plan, he just takes one step at a time I guess. He only thinks about going somewhere to play. I keep telling him to learn some skills and knowledge, but he always says, "It's very annoying to hear this."

Q: Will he stay at the Sunshine Home in the future?

C's father: Yes, I hope he can stay there as long as he can, but the Sunshine Home has an age limit; anyone over 35 years old has to leave. I'm worried about where he would go if one day he's told to leave. Maybe there is a similar institute for older people, or the district council might set up one in the future.

At least let him go somewhere every other day to keep him busy and communicate with the outside world. Staying at home only makes him feel worse.

\section{Interview with Mr. C's Teacher}

Interviewee: Teacher Ms. Meizhen Zhou

Interviewer and writer: Yujia Feng

Interview date: December 8, 2016

Interview place: The Sunshine Home in Hongkou District

Q: How's Mr. C getting along here?

Teacher: Mr. C is ignorant when he peaks, sometimes his words can be very tough. So I told him: "Your mom is ill, your dad is exhausted, what'll happen if your dad gets sick? You've got to be your dad's assistant to help him look after your mom." After the conversation, his behavior improved, but he went back to his normal behavior after a while. When I talked to him again, Mr. C told me: "I promise I'll do what you told me this time!" Children like him, they certainly can keep their promises, but forget just as easily, so you have to repeat yourself several times to help them remember. 
Q: Do you have any regular activities at Sunshine Home?

Teacher: We have quite a lots activities going on, because we have six NGO groups volunteering here to help us. Actually, we prefer to let the students do more exercises rather than sit around in the classroom all the time.

Q: Did you notice any changes after these intellectually disabled people came here?

Teacher: Some students become more open and happier and their intelligence develops as well. Their parents are relieved with this change, because they can be very naughty: throwing stuff, fighting with the others, and so on. These students also reach a better level of communication with their parents.

Some children who missed out on family attention and socialization, might have developed mental problems; for example, some children can be affected by their parents' divorce or family indifference.

Q: How about Mr. C's performance in the drum team?

Teacher: Mr. C joined the band in 2010 for the first time, but left for a while before he came back to us last year. Compared to other students, he's new and needs to do more practice with the new dances, especially his coordination. Even though Mr. C is just mildly disabled, his reflex ability is worse than some of the moderately disabled students.

Q: What kind of Special Olympics events is Mr. C involved in?

Teacher: He joined the District's Special Olympic Sport Events in 2007 or 2008, the year he came to the Sunshine Home. He was an athlete from the Jiaxing Subdistrict team; the competition was on the campus of Fuxing Middle School. He didn't participate in the Shanghai Special Olympics World Summer Games in 2007, because for this event we only chose experienced athletes.

There are municipal and district-level Special Sports Meetings in Shanghai every year, and international games every 2 years, for these students. In our area, we have many disabled people, the Sunshine Home has around 80 students, some children over 35 years old stop coming to the Sunshine Home, but they certainly are part of our district Special Sports Meeting. Participation is the first aim of our event. Every athlete gets a small prize, even the people who aren't in the top three.

Actually, our Sunshine Home's students are just a small part of our disabled group, most of them stay at home. About $70 \%$ of the parents tend to hide their children away, they don't talk about them with anybody and they never take them out. Only $30 \%$ of children get a chance to go outside.

\section{Interview with Mr. C}

Interviewee: $\mathrm{Mr}$. C

Interviewer and writer: Yujia Feng Interview date: November 27, 2016, during the break of the drum team practice Interview place: Hongkou District Disabled Persons' Federation, Shanghai 
Q: Did you feel any different after you joined the drum team?

C: I wasn't very healthy, because I didn't exercise, I got a cold quite often, but now I'm much stronger.

Q: Why did you join the drum team?

C: Because my classmate, who joined the band earlier, told me to join them, so I did.

Q: How do you feel about the band's practice and performance?

C: I look forward to the band's performances, I'm happy to be a part of it.

Q: Did you make any new friends?

$\mathrm{C}$ : I met Lu Yi. All of us are good friends here.

Q: Do you practice drumming at home?

C: No, I don't.

Q: Did you join in sports and games before?

C: For the Sports Meeting of the Special Olympics, I did badminton, table tennis, basketball, and the 50-m sprint.

Q: What was the level of the games? Did you win any prizes?

C: It was a Sunshine Home Sports Meeting; I got a silver medal.

Q: You just told me that you didn't like to exercise before-when did you change your mind?

$\mathrm{C}$ : I changed my mind when I joined the 50-m sprint.

Q: What classes do you study at the Sunshine Home?

C: We have English on Tuesdays, drawing and dancing on Wednesdays, and we have PE on Thursdays, also Teacher Zhou teaches us to play wiser ball.

$\mathrm{Q}$ : Which class is your favorite?

C: I don't like any of these classes. But my dad told me that I had to go.

Q: What do you like to do in your leisure time?

$\mathrm{C}$ : I like music, Jay $\mathrm{Chou}^{5}$ is my favorite singer.

\section{Observation of Mr. C in the Drum Team}

Observation date: November 27, 2016

Observation place: Hongkou District Disabled Persons' Federation, Shanghai

Observer and writer: Yujia Feng

\begin{tabular}{l|l|ll}
\hline Time & Content & Observed activities & \\
\hline
\end{tabular}

\footnotetext{
${ }^{5}$ Jay Chou is a famous Taiwanese singer and songwriter.
} 
(continued)

\begin{tabular}{|c|c|c|}
\hline Time & Content & Observed activities \\
\hline \multirow[t]{3}{*}{$9: 00-12: 00$} & Practicing the side drum & $\begin{array}{l}\text { He watches other people before he } \\
\text { starts to dance. He's not very familiar } \\
\text { with the movements, so he is usually a } \\
\text { little bit later than the others. His } \\
\text { movement isn't stretched enough, and } \\
\text { his hands are lower than the teacher } \\
\text { wants. During the second practice, the } \\
\text { teacher lets Mr. C move to the end of } \\
\text { the stage, because this place is easier } \\
\text { for him to watch the others. He tries } \\
\text { his best to follow the rhythm, but in } \\
\text { the complex parts, he still looks } \\
\text { awkward }\end{array}$ \\
\hline & Dance time & $\begin{array}{l}\text { Mr. C's movements are a little bit } \\
\text { loose and he has to follow other } \\
\text { people when they practice some } \\
\text { difficult movements }\end{array}$ \\
\hline & Break time & Chats and laughs with his classmates \\
\hline 12:00-13:00 & $\begin{array}{l}\text { The volunteer teaches several small } \\
\text { groups to make chocolate cakes }\end{array}$ & $\begin{array}{l}\text { Mr. C watches his teammates make } \\
\text { the cake. The volunteer encourages } \\
\text { him to join in the cooking. So Mr. C } \\
\text { helps to put mixture in the cake tin. At } \\
\text { the end, he helps his classmates to } \\
\text { pack up the equipment and materials }\end{array}$ \\
\hline
\end{tabular}

\section{Observation of Mr. C at the Sunshine Home}

Observation date: December 8, 2016

Observation place: Jiaxing Subdistrict Sunshine Home in Hongkou District, Shanghai

Observer and writer: Yujia Feng

\begin{tabular}{l|l|l}
\hline Time & Content & Observed activities \\
\hline 9:04 & Practicing the People's Radio Calisthenics & \\
\hline
\end{tabular}


(continued)

\begin{tabular}{|c|c|c|c|}
\hline Time & \multicolumn{2}{|l|}{ Content } & Observed activities \\
\hline \multirow[t]{5}{*}{$9: 10-9: 57$} & \multirow[t]{5}{*}{$\begin{array}{l}\text { Mental rehabilitation } \\
\text { instruction }\end{array}$} & $\begin{array}{l}\text { The students stand in a } \\
\text { circle, relaxing their } \\
\text { body for exercise }\end{array}$ & $\begin{array}{l}\text { The teacher is a doctor } \\
\text { who comes from the } \\
\text { Subdistrict Center for } \\
\text { Mental Control. In the } \\
\text { workshop, the teacher } \\
\text { explains to the students } \\
\text { what "Expressive Arts } \\
\text { Therapy" is, it includes } \\
\text { several parts: a. } \\
\text { Relaxing; b. Warming; } \\
\text { c. Venting their } \\
\text { emotions through } \\
\text { actions; d. To satisfy an } \\
\text { impossible desire by } \\
\text { catching objects in their } \\
\text { imagination }\end{array}$ \\
\hline & & $\begin{array}{l}\text { Following the teacher's } \\
\text { directions, from turning } \\
\text { heads to waving hands } \\
\text { and turning shoulders } \\
\text { and body actions }\end{array}$ & $\begin{array}{l}\text { Mr. C's movements } \\
\text { aren't quite right, so the } \\
\text { teacher corrects his } \\
\text { turning shoulder } \\
\text { movement }\end{array}$ \\
\hline & & $\begin{array}{l}\text { A forward bending } \\
\text { trunk exercise }\end{array}$ & $\begin{array}{l}\text { Mr. C can't do the } \\
\text { exercise. The teacher } \\
\text { helps him to stretch his } \\
\text { legs properly and bend } \\
\text { his head down at the } \\
\text { same time. His } \\
\text { movement improves, } \\
\text { and he can bend his } \\
\text { body down better. } \\
\text { During the exercise, he } \\
\text { talks and laughs with his } \\
\text { classmates }\end{array}$ \\
\hline & & $\begin{array}{l}\text { Body swinging exercise, } \\
\text { feet kicking exercise }\end{array}$ & $\begin{array}{l}\text { He keeps his sense of } \\
\text { balance and pace most } \\
\text { of the time }\end{array}$ \\
\hline & & $\begin{array}{l}\text { "Catching up stuff" } \\
\text { exercise }\end{array}$ & $\begin{array}{l}\text { He isn't a very strong } \\
\text { person and he can't push } \\
\text { through the circle. But } \\
\text { finally he joins the } \\
\text { group with his parents' } \\
\text { encouragement }\end{array}$ \\
\hline \multirow[t]{2}{*}{$10: 10-10: 40$} & \multirow[t]{2}{*}{ Break time } & $\begin{array}{l}\text { He draws a mask on } \\
\text { paper }\end{array}$ & \\
\hline & & $\begin{array}{l}\text { He plays table tennis } \\
\text { with the teachers, } \\
\text { classmates, and parents }\end{array}$ & $\begin{array}{l}\text { He isn't a skilled player, } \\
\text { but his coordination and } \\
\text { reflex ability are pretty } \\
\text { good }\end{array}$ \\
\hline
\end{tabular}

(continued) 
(continued)

\begin{tabular}{|c|c|c|c|}
\hline \multirow[t]{2}{*}{ Time } & \multicolumn{2}{|l|}{ Content } & \multirow{2}{*}{$\begin{array}{l}\text { Observed activities } \\
\text { He's quiet and only } \\
\text { speaks when the teacher } \\
\text { asks him something }\end{array}$} \\
\hline & & $\begin{array}{l}\text { Sitting and chatting with } \\
\text { classmates and Teacher } \\
\text { Zhou }\end{array}$ & \\
\hline $10: 40$ & \multicolumn{2}{|l|}{ Lunch time } & \\
\hline 12:40-14:00 & \multicolumn{2}{|l|}{ Break time } & $\begin{array}{l}\text { In the rest room, } \\
\text { students lie down in } \\
\text { their own extendable } \\
\text { chairs }\end{array}$ \\
\hline \multirow[t]{2}{*}{ 14:00-15:00 } & \multicolumn{2}{|l|}{ Ability training: wiser ball } & $\begin{array}{l}\text { It's a strategic and } \\
\text { competitive game. The } \\
\text { teacher explains the } \\
\text { rules and gives a } \\
\text { demonstration }\end{array}$ \\
\hline & \multicolumn{2}{|c|}{$\begin{array}{l}\text { Mr. C comes on to the ground for the second turn } \\
\text { with his teammates }\end{array}$} & $\begin{array}{l}\text { He's trying to score a } \\
\text { goal guided by the } \\
\text { captain. He fails the first } \\
\text { time, but scores the } \\
\text { second time and the } \\
\text { team win }\end{array}$ \\
\hline 15:00 & \multicolumn{2}{|c|}{ At the end, the teacher calls all of students together } & $\begin{array}{l}\text { Mr. C packs his stuff } \\
\text { and says goodbye to his } \\
\text { teacher and classmates }\end{array}$ \\
\hline
\end{tabular}

Translated by Huili Meng Edited by Russell Murray

Open Access This chapter is licensed under the terms of the Creative Commons AttributionNonCommercial-NoDerivatives 4.0 International License (http://creativecommons.org/licenses/bync-nd/4.0/), which permits any noncommercial use, sharing, distribution and reproduction in any medium or format, as long as you give appropriate credit to the original author(s) and the source, provide a link to the Creative Commons license and indicate if you modified the licensed material. You do not have permission under this license to share adapted material derived from this chapter or parts of it.

The images or other third party material in this chapter are included in the chapter's Creative Commons license, unless indicated otherwise in a credit line to the material. If material is not included in the chapter's Creative Commons license and your intended use is not permitted by statutory regulation or exceeds the permitted use, you will need to obtain permission directly from the copyright holder.

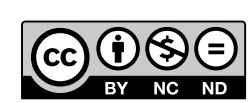

